\title{
Notas para uma curadoria transviada
}

\author{
Notes for a Queer Curatorial Practice
}

\author{
Notas para una curaduría marica
}

Guilherme Altmayer (Pontifícia Universidade Católica do Rio de Janeiro, Brasil) *

https://doi.org/10.22409/poiesis.v21i35.40409

\begin{abstract}
RESUMO: O presente texto aporta algumas reflexões críticas a partir da experiência de curadoria da mostra sexo e gênero dissidente Os Corpos são as Obras no Rio de Janeiro, no espaço independente Despina, em 2017. Em um percurso que passa pela localização do próprio corpo bixa e homem-cis-branco para pensar práticas curatoriais como agenciamento, e artes e ativismos transviados como ferramentas de insurgência do corpo à cisheteronorma, relatarei sobre algumas das questões e inquietações suscitadas no processo de ativação da mostra que, espero, possam contribuir para que o fazer curadoria siga sendo tensionado e revisitado.
\end{abstract}

PALAVRAS-CHAVE: arte e ativismo; sexualidade; gênero; curadoria

* Guilherme Altmayer é curador e doutor em Design pela Pontifícia Universidade Católica do Rio de Janeiro. E-mail: galtmayer@gmail.com. Orcid: https://orcid.org/0000-0002-4789-7949 
ABSTRACT: The present text proposes some critical reflections from a curatorial experience of a sex and gender dissidence art exhibition called Os Corpos são as Obras, which happened in Rio de Janeiro, at Despina, in 2017. On a journey that begins by locating my own faggot cis-white-man body in the process, we will think of curatorial practices as agency and queer arts and activism as tools for insurgency of bodies to the cisheteronormativity. I will then report on some of the questions and concerns raised in the process of activating the show that I hope can contribute for curatorial processes to be continuously provoked and revisited.

KEYWORDS: art and activism; sexuality; gender; curatorship

RESUMEN: El presente texto propone algunas reflexiones críticas a partir de la experiencia de la curaduría de la muestra de arte sexo y género disidente Os Corpos são as Obras acontecida en Rio de Janeiro, en el espacio Despina, en 2017. En un camino que empieza por localizar mi propio cuerpo marica y también hombre-cisbranco, pensaremos en prácticas curatoriales y artes y activismos cuir como herramientas de insurgencia del cuerpo a la cisheteronorma. En seguida, nos aproximamos de preguntas y preocupaciones planteadas en el proceso de activación de la muestra, que espero puedan contribuir para que practicas curatoriales puedan seguir siendo provocadas y revisitadas.

PALABRAS CLAVE: arte y activismo; sexualidad; genero; curaduría

Citação recomendada:

ALTMAYER, Guilherme. Notas para uma curadoria transviada. Poiésis, Niterói, v. 21, n. 35,

p. 17-34, jan./jun. 2020. [https://doi.org/10.22409/poiesis.v21i35.40409]

Guilherme Altmayer, Notas para uma curadoria transviada. 


\section{Notas para uma curadoria transviada}

No presente texto elaboro alguns apontamentos sobre a experiência de curadoria de artes sexo e gênero dissidentes da mostra Os Corpos são as Obras, promovida no espaço independente Despina no Rio de Janeiro em 2017, como parte do programa Arte e Ativismo na América Latina, ciclo promovido pelo espaço. Relatos de uma experiência que inicia com a localização do próprio corpo bixa e homem-cis-branco neste processo de construção, passando por uma reflexão sobre curadoria como agenciamento, e artes e ativismos transviados como ferramentas de insurgência do corpo à cisheteronorma. Em seguida, aporto algumas inquietações suscitadas no processo de construção e ativação da mostra - compartilhamento, representatividade, apagamento, ativação de obras e corpos - não para ofe- recer respostas ou um como fazer, mas para contribuir para que práticas curatoriais sigam sendo repensadas e tensionadas.

No dicionário, o termo transviado tem o seguinte significado: aquele que se transviou; que se afastou dos bons costumes; desencaminhado; que se perdeu do caminho; que se opõe aos padrões comportamentais preestabelecidos ou vigentes. Transviado é também proposto pela pesquisadora Berenice Bento (2015) para pensar em um termo "guarda-chuva" para ações sexo dissidentes de bichas, sapatões, trans, travestis e que seria uma tradução que se aproxima do "queer". Faço uso recorrente do termo para pensá-lo como lugar de contestação e tensionamento entre o campo das artes e das dissidências de sexo e gênero. 


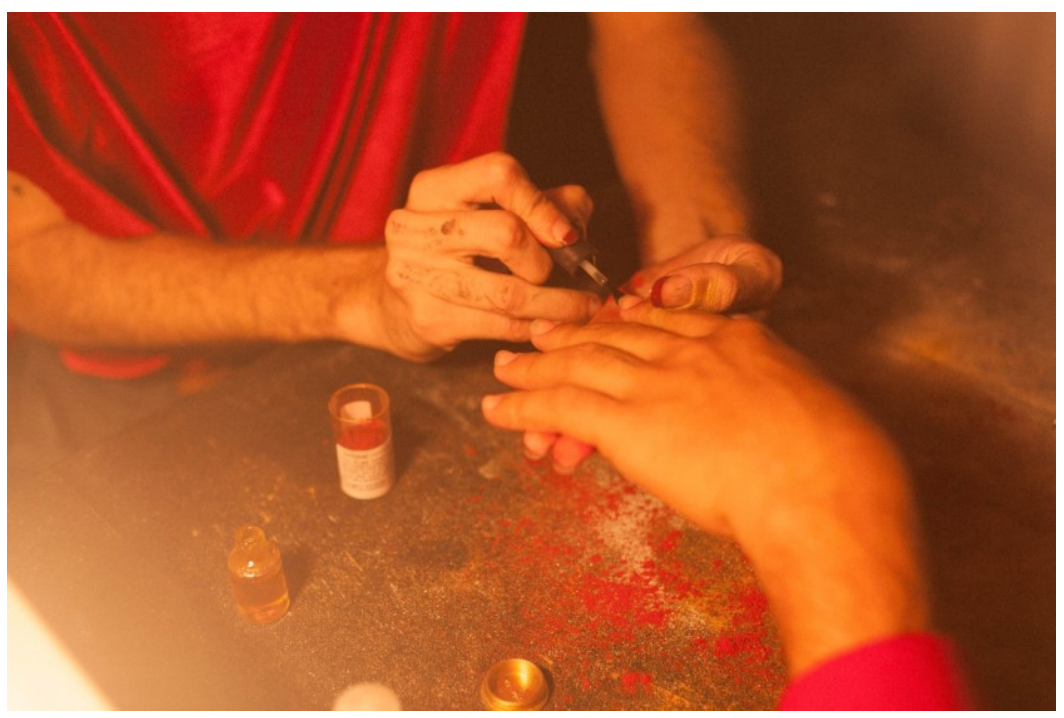

Fig. 1 - Registro do encontro NAVALHA: manicure show, concebido e curado por Ana Matheus Abbade, durante a mostra Os Corpos são as Obras no espaço Despina, Rio de Janeiro, em 2017. (Imagem: VidaFodona)

Guilherme Altmayer, Notas para uma curadoria transviada. 
Se situa bixa! Antes de adentramos nas experiências curatoriais transviadas propriamente ditas, permitam-me algumas breves linhas que apontam para a importância de localizar o lugar do curador, como uma provocação para pensar a curadoria em um caminho oposto à imparcialidade e neutralidade, que intenciona abarcar implicações éticas e políticas do próprio lugar de enunciação, sempre em relação a outros agentes com quem cria interlocução. Um exercício que me parece primordial para poder adentrar em espacialidades tão distintas e tão distantes da própria realidade. Todo processo de curadoria em artes é uma tomada de posição. Pensar curadoria ativista é reconhecer essa tomada de posição como lugar político de atuação, neste caso, a bixa que vos fala (que também é cis, é homem, é branco) e como esse lugar molda em certa medida minha compreensão de mundo e, portanto, demanda práticas de alteridade para adentrar territórios de estranhamento da própria maneira de pensar: zonas de desconforto.

Um estranhamento que passa por uma tomada de consciência de como o lugar que ocupo é um lugar que silencia e invisibiliza muitos outros corpos subalternizados. Pergunto: como então estabelecer alianças e relações com outros corpos entendendo que estão vigentes estruturas hierárquicas que produzem injustiças e desigualdades sociais atravessadas por questões de raça, gênero e classe?

Tomar consciência desse lugar é, acima de tudo, uma compreensão da necessidade de criticar a própria fala, em um fluxo constante de aprendizado que envolve errar e praticar exercícios de revisão de privilégios: aprender quando silenciar, aprender a quem escutar, aprender a ceder o lugar, saber se retirar. Sobretudo, analisar o próprio olhar e estranhar:

Não parar nunca de se perguntar o que estamos fa21 zendo em nosso jardim secreto, com nós mesmos, com as pessoas que queremos [...] com as ideias, com o mundo: com esses milhares de mundos que nos rodeiam e que dançam jubilosamente melodias próprias que nem sempre se entende. Eébom que seja assim, porque é graças a este desconhecimento, a esse "outro" inalcançável e que se situa fora de si mesmo, que se define a alteridade. (NORAMBUENA, 1998, p. 20)

Esta experiência curatorial me permitiu entender o quanto o lugar político da bixa não basta, por si só, para garantir legitimidade, nem tampouco necessariamente abre cami- 
nho para configurar canais de interlocução com tantos outros corpos. Este é um processo que demanda construção de confiança, aprofundamento das relações e trocas, criação de aliança na diferença e, principalmente, o compartilhamento dos procedimentos curatoriais.

Processo que passa também por escutar movimentos negrxs e trans no que diz respeito a branquitude e cisgeneridade, essas violentas condições estruturais e sistemáticas, que ditam normas e garantem privilégios à muitas pessoas cisbrancas, por meio do estabelecimento de certo habitar de um lugar dado como "natural", socialmente construído ao longo dos períodos "coloniais" e "imperialistas" e que segue vigente nos tempos atuais. Cabe às pessoas cisbrancas (aqui me incluo), buscar entender, dar a ver e delimitar os efeitos e materialidades produzidos por essas relações (Schucman, 2014) que são também sustentáculos da abissal desigualdade racial no Brasil.

Para Donna Haraway (1995), em Saberes Localizados: a questão da ciência para o feminismo e o privilégio da perspectiva parcial, uma proposta epistemológica de saber situado é uma ação política que reconhece e evidencia que a produção de conhecimento não está descontextualizada nem muito menos desligada da subjetividade de quem a realiza. Relatar o ponto de onde partimos é atestar que não existe neutralidade no ofício de curador-pesquisador, bem como leva em consideração que, em realidades tão diversas, é preciso compreender que são muitos os olhares possíveis para analisá-las. (HARAWAY, 1995)

Não se trata tampouco de validar que tudo pode o curador que se coloca e que se localiza. Muito pelo contrário, a pesquisadora feminista frisa que esse não é um lugar isento de reavaliação crítica, de desconstrução e interpretação. Até porque, segundo ela, a visão é sempre uma questão do poder de ver e de uma violência implícita em nossas práticas de visualização: "com o sangue de quem foram feitos meus olhos?" (HARAWAY, 1995 p. 25), a autora questiona. A essa pergunta, podemos agregar muitas outras derivadas das relações de poder que operam nestas práticas: de que forma e a partir de onde é possível ver? Para que e com quem? Qual a amplitude do campo visual? Quais outros sentidos estamos usando além da visão? Quantos corpos são invisibilizados por essas práticas? 
Atravessado por estes questionamentos e inquietações, prossigamos para algumas reflexões acerca da curadoria como agenciamento, artes transviadas e algumas das questões surgidas a partir da experiência de construção da mostra Os Corpos são as Obras.

Curadoria, do latim curator, quer dizer aquele que tem cuidado, apreço. Cuidado como lugar de escuta e de agenciamento de vozes, mais do que um lugar de fala e dominância. $E$ é neste sentido que gostaria de pensar aqui uma prática de curadoria transviada, em consonância com suas muitas atribuições no campo das artes: agenciamentos, envolvimento, pesquisa e colaboração. Curadoria é uma tomada de posição que incorre no risco de estabelecer hierarquias de poder na organização de ideias e conceitos, que incidem diretamente em regimes de visibilidade e, portanto, é carregada de responsabilidades éticas e políticas: cuidados.

Para além das lógicas mercadológicas que o termo remete, agenciamento (SOUZA in FONSECA; NASCIMENTO; MARASCHIN, 2012), aqui, é pensado com Pedro de Souza, à luz da concepção deleuziana, segundo um processo de criação em que múltiplos agentes - humanos, não humanos - entram em ação. Ação na qual o corpo do curador está implicado na tarefa e conectado a outros corpos, a ponto de não mais se reconhecer como um ente isolado.

Agenciar não é fazer pelo outro, mas com o outro: agenciamentos coletivos de enunciação (GUATTARI, 1981) que implicam, primeiro, em uma condição ética de manutenção das diferenças e se expressam com a produção de signos. E segundo, os agenciamentos maquínicos de desejo, que não propõem a reprodução, mas sim a criação de subjetividades e os meios nos quais elas passam a existir (SOUZA in FONSECA; NASCIMENTO; MARASCHIN, 2012).

À luz do que Deleuze (1998) descreve como estilo de escritura, gostaria de propor pensar curadoria como agenciamento, como atos que comportam tanto o indivíduo que escreve (cura) quanto a língua (corpos performáticos, obras de artes) que ele ativa para escrever. $O$ que se cria nesse agenciamento maquínico, longe de uma produção de bens, é um estado de mistura de corpos, de colocar um em relação ao outro, abarcando tretas e alianças, atrações e repulsões, simpatias e antipatias e compartilhamentos (DELEUZE \& GUATTARI, 2007). 
As práticas curatoriais de artes transviadas aportadas na presente escrita, a partir da mostra Os Corpos são as Obras, tratam de pensar na confluência entre pesquisa e disposição de obras de arte contra canônicas em uma estrutura expositiva somada à promoção de encontros de corpos transviados em uma série de eventos de ativação das obras e proposições performáticas. Intenciona também pensar essas convergências curatoriais como ações estéticopolíticas que tencionam um sistema das artes majoritariamente cisheterobranca (homo também, em grande medida) com proposições de outros fazeres políticos a partir de práticas compartilhadas, lançando um olhar sobre as artes (propositalmente no plural) como práticas micropolíticas, conformadoras de contracondutas de ataque ao policiamento dos corpos submetidos à cisheteronorma.

Arte é coisa de viado. De sapa, travesti, trans e manas também. Utilizo o termo arte no plural para pensar o encontro entre artes díspares e abjetas, que se manifestam em um campo expandido, são geradas a partir de práticas ativistas, e fazem uso de suportes e formatos usuais e pouco usuais
- canais do YouTube, pichações, pinturas, ocupações de rua, lambe-lambes, faixas, esculturas, instalações etc.

É a atribuição de um nome, uma identidade arte queer, arte cuir, arte bicha, arte trans que não está em questão aqui. Os efeitos da compartimentalização, delimitação a partir de um nome, de uma categoria, já são conhecidos. Pensar políticas identitárias de sexo e gênero nas artes pode momentaneamente fortalecer certos movimentos, mas, ao mesmo tempo, engessar e isolar, prevenindo sua infiltração nas lógicas estruturais dominantes do sistema, nas quais se dão relações de poder em que interessa encapsular mais do que se deixar penetrar. Assim, ao mesmo tempo que podemos notar - nos últimos anos, a década de 2010, principalmente - um estímulo às práticas gênero e sexo dissidentes nas artes, interessa também, muitas vezes, localizá-las em um "gueto" identitário, e mais, buscar manter o corpo marginal e abjeto, longe disso.

Dessa feita, interessa aqui pensar a reunião de uma multiplicidade de expressões estético-políticas transviadas como práticas não higienizadas, contra canônicas como estratégias de perturbação do dispositivo arte contemporânea desde dentro, a partir da

Guilherme Altmayer, Notas para uma curadoria transviada. 
penetração, do desconforto e do gozo. Não se trata de criar um movimento paralelo, identitário e fechado, ainda que a ameaça esteja sempre à espreita, mas sim pensar um movimento de desmonte das estruturas hetero e homonormativas, das bases de sustentação, pilares fundamentais das lógicas do capital.

Nossos corpos - atravessados pelos dispositivos que nos constituem como indivíduo em relação social, território de inscrição e regulação da norma social - são também um lugar de enfrentamento à norma, nos diz Michel Foucault (1993). Corpos que, conscientes dos efeitos violentos dos dispositivos que nos atravessam, constituem e regulam - família, escola, governos, medicina, psicologia, instâncias jurídicas e religião -, tornam-se potência latente de apropriação e manipulação desses mecanismos para se converter em geradores de novos sentidos, territórios de ocupação contranormativos e insubordinados. Assim, os corpos transviados e suas manifestações estético-políticas se convertem em território de enunciação, enfrentamento crítico e insubordinado às normas dos regimes de poder. Poder que se localiza fora e dentro, penetrando nossas entranhas e se reprodu- zindo, nos moldando, castrando e normatizando comportamentos.

A cisheteronorma busca uma coerência limitadora dos corpos, pressupõe uma fixação binária (homem/mulher, homossexual/heterossexual, cis/trans) em suas relações para reforçar a frágil matriz cisheterossexual inteligível. O resultado: corpos normais e corpos abjetos, socialmente marginalizados, estigmatizados e tidos como ameaças à disciplina estabelecida pelo "natural". A dissidência de corpos que emitem outros códigos, outros arranjos do desejo social e discordantes dos promovidos pela norma, que configuram práticas insurgentes. Práticas estético-políticas são ferramentas possíveis de ataque, de desobediência, abrindo espaços para pensar outras maneiras de estar, de desenho do próprio corpo e de sobrevivência - plataformas móveis que perturbam a ordem sexo-gênero política que interessa ao sistema produtivista do capitalismo.

Não podemos ser ingênuos e pensar que o sistema das artes é "livre" e está imune destes mecanismos de controle dos corpos. Pelo contrário, esse campo configura um dispositivo perverso que perpetua práticas exclu- 
dentes, normaliza movimentos de liberdade no intento de se manter intocável. Pensar práticas curatoriais transviadas na arte demanda que o mesmo sistema no qual se pretende penetrar possa ser tensionado.

Nesse sentido, o Coletivo 28 de Maio composto pelas pesquisadoras Mariana $\mathrm{Pi}$ mentel e Jorge Vasconcellos, em seu contra manifesto $O$ que é uma ação estéticopolítica? (2017) - promove um debate com o sistema de artes para definir o que elas chamam de ação estético-política: uma tomada de posição política anticapitalista contra o mercado das artes, uma "contra-arte". Para o Coletivo, não importa mais se são artistas ou não, se algo é arte ou não, mas sim quais redes foram construídas, e quais os riscos e efeitos que são possíveis de nos afetar. Ainda de acordo com o Coletivo, uma ação estético-política é uma prática que pode ser realizada por qualquer pessoa: é arte sem artista. É da ordem da práxis - no sentido mais radical da relação entre teoria e prática que demanda uma tomada de posição política frente às urgências de nossos tempos (28 DE MAIO, 2017).

A busca, então, é pelo deslocamento do lugar do artista. Mesmo que uma ação dessa natureza tenha sido executada por um artista, isso não importará, porque o que está em jogo é o que se instaurou por intermédio da ação, "uma zona de indiscernibilidade". (28 DE MAIO, 2017, p. 194) Algo que não permite saber se se trata de arte ou protesto, mas que se trata de agir, ativar e ser ativista: "ativismo é agir". A ativação de um campo de forças e o olhar para os efeitos que produz no campo social, e o modo que pode ser reapropriada, reproduzida. E os efeitos que produz no sistema das artes. Para o coletivo uma ação estético-política: "incide e embaralha a partilha do sensível vigente dando ensejo ao que denominamos um dispositivo de subjetivação artista. Isto é, à possibilidade de invenção e experimentação de outros modos de vida" (28 DE MAIO, 2017, p. 195).

Dessa feita, os agenciamentos da mostra em questão passaram por pensar em ações estético-políticas como práxis de ativação de novos processos de subjetivação, coletivizados, produtores de memória coletiva que fortalece ancestralidades transviadas negadas: arte-ferramenta dos e para os corpos. Passagens de potência ao ato, ou seja, devires insubordinados: devir bicha, devir sapatão, devir travesti, devir mulher, 
devir animal - múltiplas maneiras de inventar novas sensibilidades e inteligências da existência, novas relações de afeto e sobrevivência (GUATTARI, 1981).

Esses olhares são de grande ajuda para refletirmos sobre a configuração de espaços de autorrepresentação através da reunião de obras de arte e dos múltiplos corpos agenciadores de encontros na mostra OS Corpos são as Obras, que evidenciam os modos de construção de uma rede transviada do comum, na diferença, como um conjunto heterogêneo, de natureza policêntrica e caráter centrífugo. Vamos a ela.

Os Corpos são as Obras. A convite de Consuelo Bassanesi, diretora do espaço Despina, e do curador Pablo León de La Barra, com quem fui cocurador, construímos uma mostra de artes sexo e gênero dissidente como parte do segundo ciclo de Arte e Ativismo na América Latina, que tinha como tema naquele ano o corpo. O processo de construção da mostra suscitou questões que se reproduziram como que em irradiações, tais como: que questões políticas transviadas deveríamos e poderíamos abordar? Como lidar com a representatividade frente a tantas ques- tões complexas e interseccionais? Como decidir quais corpos deveriam estar presentes (e por isso, quais seriam excluídos)? Como articular a autorrepresentação? Como garantir a remuneração equitativa de todos os corpos convidados?

Essas perguntas funcionaram como norteadores, como proposições éticas levadas em consideração em todas as decisões tomadas. Não fomos capazes de responder a todas, aliás falhamos em muitas, mas tê-las como meta já nos possibilitava pensar caminhos possíveis.

Curar, nesse sentido, se tornou evidente, então, que se tratava também sobre a complexidade de lidar com uma diversidade tão grande de corporeidades, configurações políticas, a partir do lugar de privilégio um lugar que demanda cuidado e sensibilidade para se construir uma ética comum para as abordagens -, e da importância central de saber quando desaparecer para que outros possam falar por si mesmos.

Entendemos que as práticas de curadoria teriam de ser repartidas com muitas pessoas com quem estabelecemos aliança e que tinham acesso a universos e campos com os quais nossos repertórios e vivências não 
necessariamente comunicavam. Assim, a diversidade de abordagens na mostra se tornou possível também a partir do momento em que múltiplas camadas curatoriais foram colocadas em prática: através dos saberes compartilhados por Nathalia Gonçales e Andiara Ramos, que aportaram uma potente curadoria de produções audiovisuais pós-pornográficas sul-sul; pela pesquisadora feminista Nataraj Trinta, que contribuiu na seleção de filmes sobre Luz del Fuego para a noite naturista do Corpo $\mathrm{Nu}$ em homenagem a pioneira do naturismo no Brasil; a rede de corpos performáticos reunidas pela artista Ana Matheus Abade, na noite celebração NAVALHA: manicure show; os saberes da mitológica transformista Lorna Washington na "fechação" da mostra no clube Turma OK.

Entre encontros e obras, a mostra resultou em um experimento vivo, na medida em que se constituiu como um arvoramento de inter-relações que se descortinaram da convergência de distintas experiências transviadas que corporificaram-se em uma série de obras, encontros, debates, aulas, oficinas, cineclube, shows de transformista, quadrilha junina, procissão, festa, articulação entre ativismos e exposição de arte.
Mais de 50 agentes transviados foram reunidos para expor e promover, ao longo de quatro semanas, seis grandes encontros para pensarmos esse tempo e espaço: o Rio de Janeiro em 2017.

Por sugestão de Pablo, a mostra foi intitulada Os Corpos são as Obras, inspirada na performance $O$ Corpo é a Obra do artista Antonio Manuel. Assim lia-se o primeiro parágrafo do texto curatorial: "Em 1970, na abertura do 190 Salão Nacional de Arte Moderna (MAMRJ), o artista Antonio Manuel se despiu e desfilou seu corpo nu pelo espaço, para apresentar seu corpo como uma obra que, mesmo não sendo selecionada pelo júri, ficou marcada como protesto contra as ações repressivas da ditadura militar - "um exercício experimental da liberdade", nas palavras do crítico de arte Mário Pedrosa. Desde então, muitas foram as narrativas criadas em torno de "o corpo é a obra", porém poucas mencionam que o artista executou a ação ao lado de outro corpo, seminu: o de uma mulher, negra, de nome Vera Lúcia Santos".

Esta última frase, que aponta a participação de Vera Lucia Santos na ação, somente foi incluída no texto horas antes da abertura da mostra. Nenhuma das fontes de pesquisa utilizadas - Enciclopédia do Itaú Cultural, 
Memórias da Ditadura, Escritório de Arte e a Revista Brasileiros, mencionava sua participação na ação. Este novo apagamento que estávamos prestes a repetir só foi evitado por conta de um comentário da curadora Marta Mestre em um post do Facebook, que nos alertou da participação de Vera e nos instigou a investigar mais a fundo sobre a ação. Com a ajuda do curador Raphael Fonseca, tivemos acesso a tese CONTRAARTE: vanguarda, conceitualismo e arte de guerrilha - 1969-1971, de Artur Freitas (2017) onde o pesquisador descreve a ação de Antonio Manuel em detalhes, e com múltiplos ângulos que narram a participação de Vera, convidada por Antonio, bem como as reações da imprensa e da crítica de arte de então. Freitas (2007) é cuidadoso ao abordar não apenas a ação em si, mas também suas reverberações na mídia de massa e no sistema operativo das artes. Em muitos dos relatos colhidos pela imprensa da época, Vera era tratada, por exemplo, como "uma mulata, encorajada, que passou a imitá-lo". (FREITAS, 2007, p. 267)

Desde o início do processo, a representatividade era uma preocupação necessária para garantir que a maior diversidade possível de corporalidades e práticas se fizesse pre- sente. Pensar números e estatísticas se torna um exercício relevante quando se trata de enfrentar políticas sistemáticas de exclusão e apagamento no sistema da arte contemporânea.

A pesquisadora feminista Maura Reilly (2018), em sua obra Ativismo Curatorial, alerta para o fato de que as lutas no campo da arte estão longe de conquistadas, no que tange uma certa equidade de gênero e raça. A arte ocidental, segundo ela, segue sendo coisa primordialmente de macho branco (REILLY, 2018). Para Reilly (2018), ainda que muitos esforços decoloniais venham sendo realizados por movimentos antirracistas, feministas, queer/cuir, o mundo das artes continua excluindo sistematicamente o "outro" - artistas mulheres, transviados, negrxs. Ainda que a pesquisadora investigue representatividade em mostras, galerias e museus norte-americanos e europeus, as evidências por ela indicadas nos auxiliam a pensar criticamente questões de representatividade no contexto das artes no Brasil.

Inspirada no coletivo feminista Guerrila Girls, sua intenção com a elaboração de levantamentos estatísticos é a de provocar o sistema das artes até que ele repense suas 
práticas no que diz respeito a gênero, raça e sexualidade, como um exercício que pode dar a ver práticas sexistas e racistas, estruturantes de uma supremacia majoritariamente branca blindada pelo "campo de liberdade", que busca se preservar a qualquer custo. Cito alguns dados estatísticos apontados por Reilly (2018): a Bienal de Veneza de 2017 contou com somente 35\% de artistas mulheres. A situação piora quando se trata de representatividade negra: apenas 5 dos 120 artistas eram negrxs (REILLY, 2018). Outro exemplo apresentado é a Bienal do Whitney, de 2014, com o tema America is Hard to See - ou "América é difícil de ver" -, a qual, paradoxalmente, contou com $69 \%$ de artistas homens e $77 \%$ do total eram de pessoas brancas.

Inspirado no trabalho das Guerrilla Girls e de Maura Reilly, busquei realizar alguns exercícios semelhantes com algumas mostras recentes no Brasil, as quais, assim como Os Corpos são as Obras, trabalham relações entre arte, gênero e sexualidade: Queermuseu e Histórias da Sexualidade. Trata-se de análises que podem ser entendidas como essencialistas e binárias - homens $x$ mulheres, negrxs $x$ brancxs - e, portanto, incapazes de lidar com a comple- xidade de contornos e corporalidades, mas que entendo serem pertinentes como alerta às disparidades alarmantes e à necessidade de pensar representatividade nas práticas curatoriais. Em minha pesquisa utilizei métodos desprovidos de "rigor científico", que incluía buscas por fotos na internet e associação do gênero aos nomes das artistes.

Na mostra Queermuseu - em 2018 na Escola de Artes Visuais do Parque Lage -, dos 81 artistas listados no catálogo da mostra, 73\% eram homens e $27 \%$, mulheres. Dos 72 artistes sobre os quais obtive resultados nas buscas, apenas um era negrx. Já a mostra Histórias da Sexualidade, no Museu de Arte de São Paulo em 2017, alcançou uma meIhor distribuição de gênero entre as artistes: $50 \%$ homens e $50 \%$ de mulheres. No entanto, a representatividade branca predominou, com um total de $85 \%$ de artistes.

Retornemos agora à mostra Os Corpos são as Obras para dar a ver números a ela pertinentes, e como, em grande medida como efeito dos exercícios de curadoria compartilhada já descritos, garantimos uma participação majoritária de pessoas trans e mulheres. Um levantamento que, diferente dos números acima citados, permitiu que a aferição de repre- 
sentatividade abarcasse maior complexidade dos corpos presentes. Das 50 agentes participantes - entre artistas contemporâneos, performers e transformistas, curadores, youtubers, treinadores de autodefesa muay thai, ativistas políticas, idealizadoras audiovisuais, personagens históricas - 18 eram pessoas trans e travestis, 17 manas cis e/ou sapas, 12 bixas cis e 3 homens cisheterossexuais. Deste total, $70 \%$ eram pessoas brancas e 30\% negras, apontando uma evidente deficiência de representação no que concerne artistas negrxs, sobretudo quando consideramos que pessoas brancas compõem uma parcela minoritária da população Brasil.

Procurei também fazer esse breve levantamento subvertendo um pouco as letras da sigla das identidades LGBTI+, substituindo o $\mathrm{L}$ por sapas e o $\mathrm{G}$ por bixas - termos pejorativos que abrem margem para pensar esses lugares para além de uma identidade fixa, e sim como ponto de partida dissidente.

A partir dessa multiplicidade de corpos, as diversas agentes participantes da mostra deram a ver um recorte bastante diverso de aproximações contra normativas contestatórias às normas de gênero e sexualidade, práticas antirracistas e também, direta e indiretamente, em diferentes medidas a machismos, classismo e xenofobias: práticas queer, cuir (sul-sul), kuir (anarco-punks marginais), transfeministas e feministas, não necessariamente nessa ordem e tampouco de forma igualitária.

Muitas das práticas presentes na mostra atuam em campos mais marginais e radicais, que não se pretendem assimilar pelo sistema das artes - e aí que reside sua potência contestatória. Outras práticas são mais conciliatórias, e não por isso menos provocadoras, e objetivam integrar o sistema operativo das artes. E há ainda algumas que são trazidas para o campo das artes, mas que não têm relação direta com ele. Os encontros entre diferentes abordagens, de acionamento concomitante, não se deram desprovidos de tensões nas próprias práticas em relação. Erros e acertos se intercalaram e se complementaram em um processo de aprendizado na zona de desconforto, em território movediço. Tensões entre práticas identitárias e contra identitárias, como uma metodologia não disciplinada que insiste em desobedecer a qualquer tipo de fechamento lógico. 
Entre as muitas proposições, navegamos no espaço expositivo entre obras como os DVDs pós-pornô piratas de Bruna Kury; a bandeira BAFO1 de Tertuliana Lustosa que subverte Simone de Beauvoir e inscreve: "Não se nasce mulher, torna-se traveca"; os processos de cura e refundação do mundo de Kleper Reis em CU É LINDO; a cronologia de ativismos transviados a partir da ressignificação do triângulo rosa, do colombiano Carlos Motta; a reunião de zines feministas produzidos no Brasil, curada pela investigadora Camila Puni; a pintura de Victor Arruda, um dos pioneiros no Brasil em abordar questões de gênero e sexualidade em seu trabalho; a faixa "Eu quero votar para presidentx!" de Anitta Boa Vida, em clara alusão ao impeachment da presidenta Dilma Rousseff acontecido no ano anterior; colar Concertina Popcreto, de Lyz Parayzo, um ornamento futurista para um pescoço desejoso de fetiche e proteção, que camufla, mas quer dar a ver que porta uma arma, um instrumento de defesa.

Ao mesmo tempo que pensávamos a reunião destas práticas transviadas no Rio de Janeiro em 2017, intencionávamos promover também o encontro desses movimentos em curso com alguns arquivos de movi- mentos ativistas transviados de décadas passadas. Para tal, trouxemos algumas práticas do Movimento de Arte Pornô (1980) do coletivo Gang e Eduardo Kac que, através da pornografia, provocava o strip tease das artes e do conservadorismo dos museus. Usando diversos meios - zines, panfletos, histórias em quadrinhos -, o grupo levava o poema pornô às ruas, à praia, às festas em plena ditadura militar; as edições originais de O Lampião da Esquina (19781981), primeiro jornal de ativismo político guei, lésbico, travesti de circulação nacional, e a flâmula do clube social Turma OK, em funcionamento desde 1962, na Lapa.

Desde o início do processo de pensar a mostra, recordando que o tema proposto partia do "corpo", entendemos que ela não poderia se ater à exposição de obras de arte. Ainda que uma obra de arte possa representar, desconstruir e comunicar os corpos, entendo que ela não olha no seu olho com a mesma intensidade que as possibilidades de encontro entre corpos, suores, sensualidades e diferenças podem proporcionar. Nossa intenção era que tanto o espaço de convivência quanto as obras fossem ativadas pelas agentes participantes e pelas tantas corpas que por lá deram close e des- 
ceram até o chão: obras-corpo, corposobra.

Cito alguns processos de ativação acontecidos durante a mostra: não assistimos vestidos aos documentários sobre o naturismo pioneiro de Dora Vivacqua, ou Luz del Fuego. Nos desnudamos e convivemos nossos corpos em pele em uma noite naturista no espaço expositivo da mostra; não apenas exibimos a flâmula do legendário clube social Turma OK, o clube social LGBTI+ mais antigo do Brasil, mas realizamos uma procissão com a peça, abrindo o caminho até chegar ao espaço na Rua dos Inválidos, em um ritual de "fechação" da mostra para socialização, jogos de bingo e shows de transformista organizado por Lorna Washington em homenagem a travesti Luana Muniz.

O coletivo Xica Manicongo expôs suas xilogravuras e distribuiu gratuitamente seus cordéis, e realizou a ocupação SerTransneja na noite de abertura, com a leitura dos cordéis pelas travestis do coletivo e a promoção de uma quadrilha junina que incluía as menines da CasaNem. Já a artiste Ana Matheus Abade, em uma de suas obras, estabeleceu processos alquímicos de maturação de reforçadores de unha ao longo de toda mostra para, ao final do processo, os utilizar para receber e proteger, com seus cuidados de manicure, as performers Uhura Bqueer, Vinícius Pinto Rosa, Michelly, Ventura Profana e Jhonatta Vicente na sua noite NAVALHA: manicure show.

Mais uma vez, o recorte definido para a mostra, Rio de Janeiro em 2017, se deu em grande medida também pela restrição orçamentária, com a qual conseguimos fazer alguns pequenos milagres. Dispúnhamos de $\mathrm{R} \$ 4.000,00$ para a execução do projeto. Frente a essa limitação, eu e Pablo decidimos que o montante total desse orçamento seria dedicado à produção e apoio logístico para as participantes. Entendemos também que nenhuma delas poderia ficar sem ao menos uma pequena verba, que podia variar entre cachê, produção ou apoio (alimentação e transporte). Assim, a distribuição do montante orçamentário se deu em função das demandas de produção de alguns dos trabalhos, das necessidades pessoais específicas de artistes/ ativistes, e do apoio ao clube social Turma OK, onde se deu a noite de encerramento da mostra. Dessa feita, a distribuição da verba disponível, aquém da desejada e merecida frente às potências produzidas pelos corpos enredados nesse projeto, se deu da seguinte forma: 
Produção das obras:

Suporte participantes / performers:

Clube social Turma OK:

$\mathrm{R} \$ 2.070,00$

$R \$ 2.200,00$

$\mathrm{R} \$ 600,00$

$\mathrm{R} \$ 4.870,00$

Por fim, gostaria de pensar que os resultados da curadoria compartilhada da mostra Os Corpos são as Obras, como uma configuração agenciada de escutas, de muitas vozes e visualidades e os apontamentos e questões aqui colocados, podem colaborar para encardir e deixar marcas no cubo branco da arte e suas práticas curatoriais. Como reunião de dissidências, pelo amplo escopo de tipologias expressivas e pela participação de pessoas que deram a ver suas realidades de contexto socioculturais e econômicos tão diversos, é

didos nesse encontro, ainda que conscientes das tantas práticas e representações que não demos conta de abordar.

\section{Referências}

28 DE MAIO, Coletivo. O que é uma ação estético-política? Revista Vazantes, UFC, v. 1, n. 1, 2017. Disponível em http://periodicos.ufc.br/vazantes/article/view/20463. Acesso em 15/10/2019.

BENTO, Berenice. Queer o quê? Ativismo e estudos transviados. Revista Cult, n. 193, agosto 2014. Entrevista. Disponível em http://revistacult.uol.com.br/home/2014/1 0/queer-o-que-ativismo-e-estudostransviados/. Acesso em 11/10/2019.

DELEUZE, Gilles; GUATTARI, Felix. Mil Platôs, vol. II. São Paulo: Editora 34, 2007. FOUCAULT, Michel. Microfísica do poder. $11^{\text {a }}$ ed. Rio de Janeiro: Graal, 1993.

FONSECA, Tania; NASCIMENTO, Maria; MARASCHIN, Cleci (Org.). Pesquisar na diferença: um abecedário. Porto Alegre: Sulina, 2012.

FREITAS, Artur. Contra-arte: vanguarda, conceitualismo e arte de guerrilha - 19691973. Paraná, 2007. 362p. Tese de doutorado. História, Universidade Federal do Paraná.

GUATTARI, Felix. Revolução molecular: pulsações políticas do desejo. São Paulo: Brasiliense. 1981.

HARAWAY, D. Saberes localizados: a questão da ciência para o feminismo e o privilégio da perspectiva parcial. Cadernos Pagu, n. 5, p. 7-41, 1 jan. 1995. Disponível em https://periodicos.sbu.unicamp.br/ ojs/index.php/cadpagu/article/view/1773. Acesso em 10/1/2020.

NORAMBUENA, Miguel Denis. Introducción. In GUATTARI, Félix. El devenir de la subjetividad. Santiago: Ediciones Dolmen, 1998.

REILLY, Maura. Curatorial Activism: Towards an Ethics of Curating. Londres: Thames and Hudson, 2018.

SCHUCMAN, Lia Vainer. Branquitude e poder: revisitando o "medo branco" no século XXI. Revista da Associação Brasileira de Pesquisadores/as Negros/as, v. 6, n. 13, p. 134-147, jun. 2014. ISSN 2177-2770. Disponível em http://abpnrevista.org.br/ revista/index.php/revistaabpn1/article/ view/155. Acesso em 11/10/2019. 